\title{
History, presence, and future of mitomycin C in glaucoma filtration surgery
}

Citation for published version (APA):

Wolters, J. E. J., van Mechelen, R. J. S., Al Majidi, R., Pinchuk, L., Webers, C. A. B., Beckers, H. J. M., \& Gorgels, T. G. M. F. (2021). History, presence, and future of mitomycin C in glaucoma filtration surgery. Current Opinion in Ophthalmology, 32(2), 148-159. https://doi.org/10.1097/ICU.0000000000000729

Document status and date:

Published: 01/03/2021

DOI:

10.1097/ICU.0000000000000729

Document Version:

Publisher's PDF, also known as Version of record

Document license:

Taverne

Please check the document version of this publication:

- A submitted manuscript is the version of the article upon submission and before peer-review. There can be important differences between the submitted version and the official published version of record.

People interested in the research are advised to contact the author for the final version of the publication, or visit the DOI to the publisher's website.

- The final author version and the galley proof are versions of the publication after peer review.

- The final published version features the final layout of the paper including the volume, issue and page numbers.

Link to publication

\footnotetext{
General rights Owners
rights.

- You may freely distribute the URL identifying the publication in the public portal. please follow below link for the End User Agreement:

www.umlib.nl/taverne-license

Take down policy

If you believe that this document breaches copyright please contact us at:

repository@maastrichtuniversity.nl

providing details and we will investigate your claim.
}

Copyright and moral rights for the publications made accessible in the public portal are retained by the authors and/or other copyright owners and it is a condition of accessing publications that users recognise and abide by the legal requirements associated with these

- Users may download and print one copy of any publication from the public portal for the purpose of private study or research.

- You may not further distribute the material or use it for any profit-making activity or commercial gain

If the publication is distributed under the terms of Article $25 \mathrm{fa}$ of the Dutch Copyright Act, indicated by the "Taverne" license above, 


\title{
History, presence, and future of mitomycin C in glaucoma filtration surgery
}

\author{
Jarno E.J. Wolters ${ }^{\mathrm{a}, \mathrm{b}, \mathrm{c}}$, Ralph J.S. van Mechelen ${ }^{\mathrm{a}, \mathrm{b}, \mathrm{c}}$, \\ Rana Al Majidi ${ }^{\mathrm{a}, \mathrm{b}, \mathrm{c}}$, Leonard Pinchuk ${ }^{\mathrm{d}, \mathrm{e}}$, Carroll A.B. Webers ${ }^{\mathrm{a}, \mathrm{b}}$, \\ Henny J.M. Beckers ${ }^{\mathrm{a}, \mathrm{b}}$, and Theo G.M.F. Gorge/s ${ }^{\mathrm{a}, \mathrm{b}}$
}

\begin{abstract}
Purpose of review
Mitomycin $C(M M C)$ is an alkylating agent with extraordinary ability to crosslink DNA, preventing DNA synthesis. By this virtue, $M M C$ is an important antitumor drug. In addition, $M M C$ has become the gold standard medication for glaucoma filtration surgery (GFS). This eye surgery creates a passage for drainage of aqueous humor $(\mathrm{AqH})$ out of the eye into the sub-Tenon's space with the aim of lowering the intraocular pressure. A major cause of failure of this operation is fibrosis and scarring in the sub-Tenon's space, which will restrict $\mathrm{AqH}$ outflow. Intraoperative application of MMC during GFS has increased GFS success rate, presumably mainly by reducing fibrosis after GFS. However, still 10\% of glaucoma surgeries fail within the first year.
\end{abstract}

\section{Recent findings}

In this review, we evaluate risks and benefits of $M M C$ as an adjuvant for GFS. In addition, we discuss possible improvements of its use by adjusting dose and method of administration.

\section{Summary \\ One way of improving GFS outcome is to prolong MMC delivery by using a drug delivery system.}

\section{Keywords}

Drug delivery system (DDS), fibrosis, GFS failure, glaucoma filtration surgery (GFS), mitomycin C (MMC)

\section{INTRODUCTION}

Glaucoma is the leading cause of irreversible blindness worldwide $[1,2,3]$. By 2020 , the prevalence of glaucoma is estimated to be around 80 million people worldwide [4]. High intraocular pressure (IOP) is one of the most important risk factors of glaucoma [5-7]. All current glaucoma treatment modalities aim at lowering IOP, initially with eye drops and/or laser treatment $[1,8]$. If these treatments do not have the desired effect, a surgical intervention can be performed, the so-called glaucoma filtration surgery (GFS) $[1,8-10]$. GFS is the last resort treatment option for glaucoma patients $[7,11]$. Current standard GFS techniques (e.g. trabeculectomy or long-tube glaucoma implant/shunt) have been practiced for several decades $[3,6]$ and are the most effective treatments to achieve sustained IOP reduction [9]. During GFS, an artificial passage (e.g. by placing a shunt) $[2,9,12]$ is created for drainage of aqueous humor $(\mathrm{AqH})$ from the anterior chamber into the space under the conjunctiva and Tenon's capsule, forming a filtering bleb. This procedure will increase outflow of $\mathrm{AqH}$ and reduce
IOP. GFS requires a substantial follow-up care and does not always lead to a permanent IOP reduction [13]. An important complication is the development of fibrosis (scarring) of the filtering bleb $[4,14,15,16]$, which often reduces the outflow of $\mathrm{AqH}$ through the operatively created drainage

aUniversity Eye Clinic Maastricht, Maastricht University Medical Centre + (MUMC+), Maastricht, ${ }^{b}$ Chemelot Institute for Science and Technology (InSciTe), Geleen, ${ }^{\mathrm{c} S}$ chool for Mental Health and Neuroscience, Maastricht University, Maastricht, the Netherlands, InnFocus, Inc., a Santen Company and ${ }^{\mathrm{e}}$ Ophthalmic Biophysics Center, Bascom Palmer Eye Institute, University of Miami Miller School of Medicine, Miami, Florida, USA

Correspondence to Jarno E.J. Wolters, University Eye Clinic Maastricht, School for Mental Health and Neuroscience (MHeNs), Maastricht University Medical Centre + (MUMC+), P.O. Box 5800, Maastricht, The Netherlands. +. Tel: 3143 3875406;

e-mail: j.wolters@maastrichtuniversity.nl; Theo G.M.F. Gorgels, University Eye Clinic Maastricht, School for Mental Health and Neuroscience (MHeNs), Maastricht University Medical Centre + (MUMC+), P.O. Box 5800, Maastricht, The Netherlands. Tel: +31 43 3871565;

e-mail: theo.gorgels@mumc.nl

Curr Opin Ophthalmol 2021, 32:148-159

DOI:10.1097/ICU.0000000000000729 


\section{KEY POINTS}

- In order to further reduce the GFS failure rate, we roughly have two options, either improve MMC application or develop new drugs.

- We suggest that prolonged presence of MMC may control fibrosis over a longer period of time, because repeated injections of $M M C$ have shown positive results.

- Eventually, new, less toxic GFS drugs will be developed to further increase GFS success rate.

passage; as a consequence, IOP will rise again [9]. This phenomenon of IOP rise after GFS is classified as a GFS-failure and most patients need to restart their medication and/or undergo a revision or new surgery procedure.

The introduction of mitomycin C (MMC) administration to augment the outcome of trabeculectomy in the early 1990s resulted in improved long-term IOP control [17], presumably by its antifibrotic action [12]. Currently, intraoperative MMC administration in the sub-Tenon's space with a sponge soaked in MMC is the gold standard antifibrotic treatment in GFS $[8,9]$. Additionally, the use and application of MMC in ophthalmology, especially in glaucoma procedures, has been increasing in recent years, because of its modulatory effects on wound healing [18]. Unfortunately, MMC administration does not completely prevent failures of current GFS procedures. In order to reduce the number of failures, new so-called minimally invasive glaucoma surgical (MIGS) devices and procedures have been developed and have been made available for several years [19"',20,21]. These MIGS devices are less stressful for patients $\left[19^{-\prime}, 20,21\right]$, but unfortunately also not always successful [22]. There are currently three general types of MIGS devices (implants) that shunt from the anterior chamber to, (1) Schlemm's Canal (iStent, Hydrus), (2) the supraciliary space (new devices in development), and (3) to a bleb formed under the conjunctiva and Tenon's capsule, (Allergan XEN-gel stent and the Santen PRESERFLO ${ }^{\mathrm{TM}}$ MicroShunt) which emulates GFS [21]. Importantly, MMC administration still remains necessary in GFS-based subconjunctival-based MIGS for suppressing the fibrotic reaction. Recent results show that a substantial proportion of MIGS placed in the sub-Tenon's space, augmented with MMC, still show an increase in IOP within the first year, too often leading to failure [23]. Overall, we conclude that despite the development of new GFS methods the administration of MMC is still required. A more important concern is that failure rates of the new MIGS methods with onetime intraoperative MMC administration remain relatively high.

The aim of this literature review is to evaluate the risks and benefits of MMC as an adjuvant for GFS. In addition, we discuss possible improvements of MMC use. The question is whether MMC is here to stay, is it time to adjust its way of application or is it time to find a new drug and medication regimen?

\section{MITOMYCIN C AND ITS USE IN GLAUCOMA FILTRATION SURGERY}

\section{Physical and chemical properties}

MMC was isolated from the broth of the Streptomyces caespitosus in Japan in $1954[8,17,18,24,25,26,27]$. MMC is isolated as blue violet crystals [26]. The molecular weight of $\mathrm{MMC}\left(\mathrm{C}_{15} \mathrm{H}_{18} \mathrm{~N}_{4} \mathrm{O}_{5}\right)$ is 334.33 Daltons. MMC is readily soluble in water $(0.5 \mathrm{mg} /$ $\mathrm{ml})$ and organic solvents $\left[26,28^{-}\right]$. The melting point is $360^{\circ} \mathrm{C}$ [29]. MMC solutions, in $0.9 \%$ saline, are stable for at least $6 \mathrm{~h}$ at $37^{\circ} \mathrm{C}$ [30].

\section{Reactive properties}

MMC is an alkylation agent targeting DNA, RNA, proteins, and lipids. Interestingly, MMC was postulated to have two alkylating centers, the 1,2-aziridine (C1 position) and 10-carbamate group (C10 position) (Fig. 1) [27]. As an example, the chemical reaction (reductive alkylation) with DNA is illustrated in Fig. 2, adapted from Verweij and Pinedo [26].

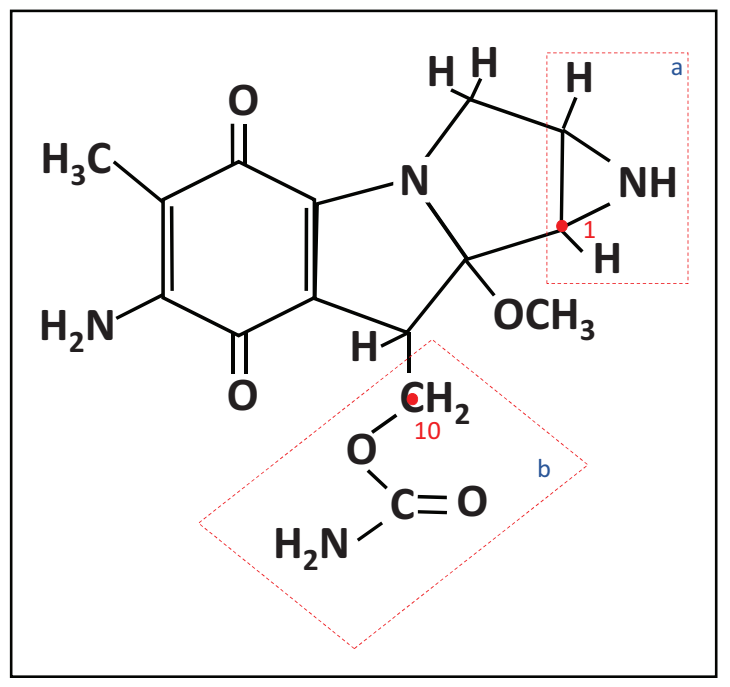

FIGURE 1. Chemical structure of MMC. (A) 1,2 aziridine with the first alkylating reactivity at the $\mathrm{Cl}$ position (see red dot), (B) 10-carbamate group with a second alkylating center at the C10 position (see red dot). 


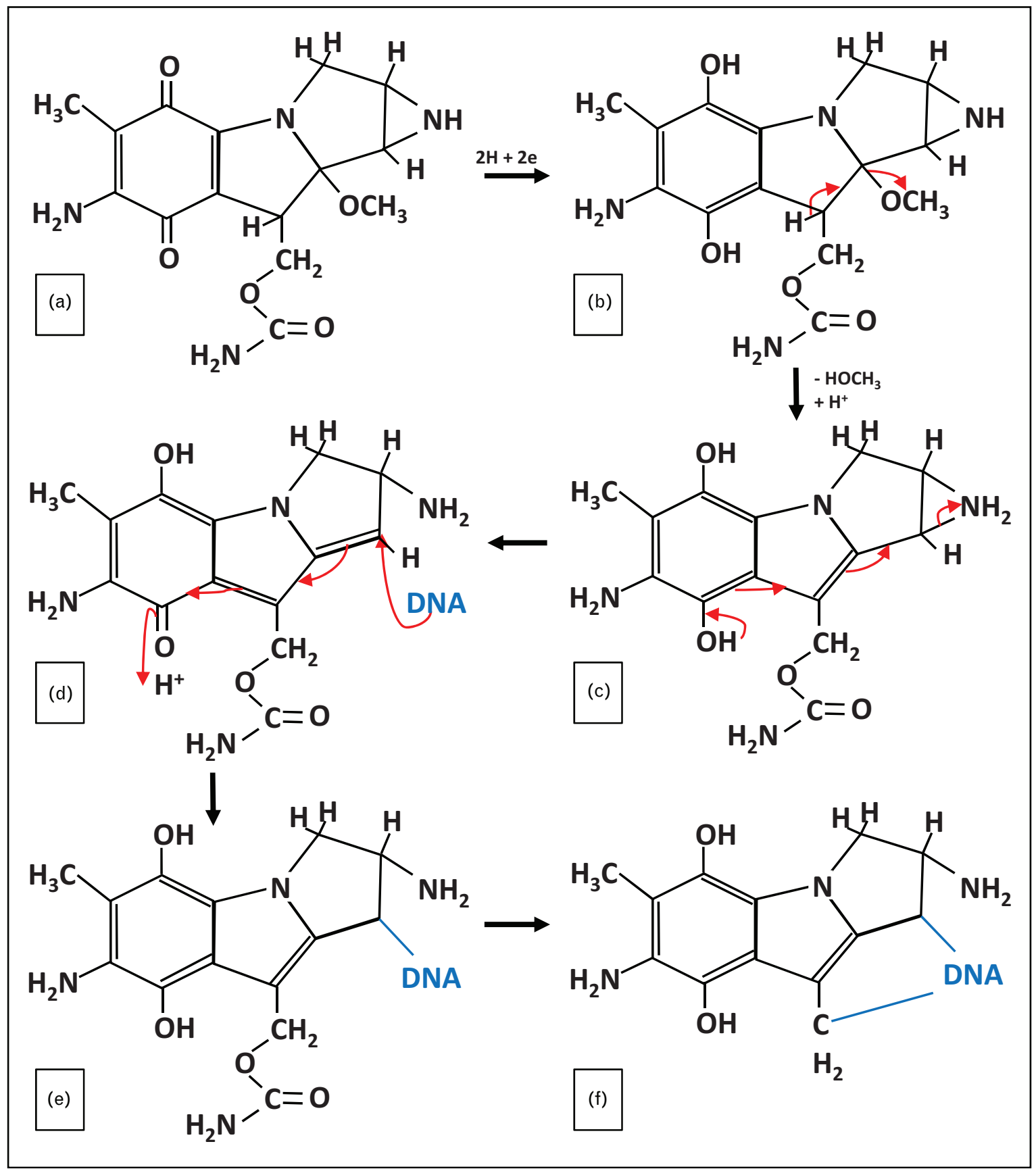

FIGURE 2. Reductive activation and DNA alkylation of MMC, adapted from Verweii and Pinedo [26]. (A) MMC, (B) intermediate of $M M C,(C)$ unstable reactive intermediate of $M M C,(D)$ quinone methide (has a high alkylating reactivity at the C1 position), (E) MMC-DNA adduct (with a second alkylating center at C10), (F) MMC cross-linked DNA adduct. MMC, mitomycin $\mathrm{C}$.

The interaction of DNA with MMC results in the alkylation of multiple DNA guanine residues [31]. The clinically used antitumor agent MMC alkylates DNA upon reductive activation and forms in this process six covalent DNA adducts [27]. First, a oneor two-electron reduction (Fig. 2A and B) occurs under anaerobic conditions, followed by a spontaneous loss of methanol that leads to the formation of an unstable reactive intermediate (Fig. 2B and C).
Thereafter, rearrangement of the reactive intermediate (Fig. 2C) will be followed by a nucleophilic addition of DNA that results in a mono-alkylated product (Fig. 2D). Intramolecular displacement of the carbamate group would then result in the crosslinked adduct (Fig. 2E and F).

Overall, DNA alkylation by MMC will block DNA synthesis and consequently inhibit cell proliferation $[8,31]$. In addition, several of the formed 
DNA adducts are capable of inducing cell death in cancer cells since they can alkylate and cross-link DNA (for review, see [27]).

Activation of MMC within the cell is influenced by several factors. First, it is known that MMC is activated by enzymatic reduction within the cell, a process mediated by cytochrome $\mathrm{P}-450$ reductase and that occurs most effectively in a hypoxic environment $[24,26]$. Second, it has been noted that MMC activation is also nicotinamide adenine dinucleotide phosphate (NADPH)-dependent [29]. Third, it is known that MMC activates the PI3K/ Akt signaling pathway in a p53-dependant manner $[27,32]$. Activation of MMC will result in alkylation/ crosslinking of DNA as shown in Fig. 2.

In addition, it has been shown that MMC crosslinks the complementary strands of the DNA double helix especially in CpG-sites $[25,26]$. Furthermore, activated MMC is most effective in the late G1- and S-phases of the cell cycle $[17,18,26]$, but is not essentially cell cycle specific [17]. Because MMC is relatively nonspecific and reacts with cells in every phase in the cell cycle, it causes cytotoxicity by lipid peroxidation and by damage to DNA and protein [33].

MMC is not only known as an alkylating agent [24,32], but also as an antibiotic [34], cross-linking reagent [35], and a nucleic acid synthesis inhibitor [36]. In addition to the specific inhibition of DNA synthesis due to alkylation, inhibition of RNA and protein synthesis seem to be nonspecific manifestations of MMC cell toxicity [26,29]. The use of MMC as an anticancer agent or as an antifibrotic/ antiadhesion agent relies on exactly the same molecular mechanism of action, namely the formation of covalent adducts of MMC with DNA [31].

\section{Common applications of MMC}

By virtue of the actions as described above, MMC is used as an antitumor, antibiotic, antiproliferative, antifibrotic, and immunosuppressive agent. The antitumor MMC has shown clinical activity in a number of cancers, including stomach cancer, breast cancer, and cervical cancer $[26,37,38]$. Furthermore, MMC is known to have immunosuppressive properties and has been shown in vitro to inhibit B-cell, T-cell, and macrophage proliferation and impair antigen presentation, as well as the secretion of interferon gamma (IFN- $\gamma$ ), tumor necrosis factor alpha (TNF- $\alpha$ ), and interleukin (IL)-2 [36]. Despite these properties it is not often used as an immunosuppressive agent in the clinic. Its use in ophthalmology has been increasing in recent years, because of its modulatory effects on wound healing (antiproliferative, antifibrotic) [18]. In this application,
MMC leads to an almost complete inhibition of fibroblast proliferation [24] and therefore a significant reduction of fibrosis [39].

\section{GFS and cause of failures}

Increased IOP can be caused by a myriad of factors contributing to either overproduction of aqueous humor (AqH) by the ciliary body or increased resistance in the AqH outflow paths from the anterior chamber [2]. Conventional outflow from the anterior chamber is through the trabecular meshwork into Schlemm's Canal, subsequently to the collector channels and then into the venous plexus in the sclera [2]. The secondary outflow path is into the supraciliary space and then into the venous plexus in the sclera [2]. If any of these paths are of high resistance, the IOP will become high. GFS reduces IOP by increasing the outflow of AqH out of the anterior chamber through an artificial passage that bypasses the trabecular meshwork, Schlemm's Canal, the collector channels and the venous plexus (e.g. by trabeculectomy or by placing a tube shunt) $[6,9,11]$. AqH is directed into the space under the conjunctiva and Tenon's capsule, the sub-Tenon's space, forming a filtering bleb $[6,9,11]$. Outflow from the bleb can be through the conjunctiva into the tear film or into the episcleral veins, whichever is of lower resistance [40]. The success of GFS is threatened by fibrosis of the filtering bleb, which progressively limits AqH outflow from the anterior chamber into the filtering bleb. Therefore, during GFS, surgeons use a onetime MMC administration intraoperatively within the wound bed to inhibit the postoperative formation of fibrotic and scar tissue [16]. This usually works very well in the first postoperative period. Unfortunately, despite this onetime intraoperative MMC treatment during GFS, fibrosis (scarring) occurs postoperatively and results in $5-10 \%$ failure rate every year [23]. Fibrosis, although being a part of the normal wound healing, will have the negative effect of blocking the artificial passage (for example by closing the flap or distal tube end) postoperatively $[9,15,16]$. This will result in a rise in IOP, requiring restart of glaucoma medications, an intervention (e.g. laser suture lysis, needling) or reoperation.

Wound healing and scarring is a complex process that consists of a series of events, including hemostasis (phase 1), inflammation (phase 2), proliferation (phase 3), and remodeling (phase 4) after surgical tissue trauma $[4,9,15,16]$. In more detail, the surgery starts with inducing a tissue trauma with at least some release of blood cells and plasma proteins, or hemostasis (phase 1), which will trigger a localized inflammatory response (phase 2). During 
the inflammation phase the innate immune system will be activated and inflammatory cytokines will be released. In the early inflammation phase, platelet activation provides a rich source of mediators [such as platelet-derived growth factor (PDGF), vascular endothelial growth factor alpha (VEGF-A), and transforming growth factor beta type 1 (TGF- $\beta 1$ )]. These factors enhance the recruitment of macrophages that also release different growth factors, such as transforming growth factors alpha and beta (TGF- $\alpha$, TGF- $\beta$ ), PDGF, and fibroblast growth factor (FGF). Thereafter, 1 to 3 days after surgery, the proliferation phase (phase 3 ) ensues with propagation and invading of fibroblasts (this is driven for example by PDGF). Herein, transdifferentiation of fibroblasts into myofibroblasts will be induced by the growth factor TGF- $\beta$. Finally, this will enhance the expression of extracellular matrix (ECM) proteins to strengthen the ECM (phase 4).

This normal, naturally occurring wound healing reaction can produce an adverse result in GFS when scar tissue is generated in the filtering bleb, more specifically if this scar tissue encloses the ostium and scleral flap after trabeculectomy, or the distal end of the tube implant in MIGS procedure, limiting $\mathrm{AqH}$ outflow and resorption.

\section{Introduction of MMC in GFS and its regulation}

To prevent fibrosis, MMC is applied in conjunction with GFS. In 1983, Chen et al. [41] were the first to describe the efficacy of MMC treatment in enhancing bleb survival following trabeculectomy in eyes with a high risk of failure [24,41]. The introduction of MMC treatment in trabeculectomy surgeries has improved the long-term IOP control through delayed wound healing resulting from inhibition of fibroblast proliferation [17]. Chen et al. [42] originally reported in 1990 that application of a MMC solution at a concentration of 0.2 to $0.4 \mathrm{mg} / \mathrm{ml}$ for $5 \mathrm{~min}$ is adequate, and poses little risk of severe complications such as ocular hypotony $[24,42]$. However, they also suggested that $0.2 \mathrm{mg} / \mathrm{ml}$ for $5 \mathrm{~min}$ may be the safest effective dose [42]. Later, in 1995, Hung et al. [43] investigated the use of MMC by a subconjunctival injection prior to trabeculectomy in patients with refractory glaucoma [24,43]. In 2004, a survey of British ophthalmology consultants reported that $82 \%$ of the surgeons used antimetabolites [apart from MMC also 5-fluorouracil (5-FU) is used] during trabeculectomy $[24,44]$. Finally, MMC was reported as the most commonly used antimetabolite among American Glaucoma Society members in 2008 [24,45].

Legislation of MMC-usage is different in each country. Mitosol (mitomycin for solution, $0.2 \mathrm{mg} / \mathrm{vial}$,
Kit for Ophthalmic Use) [46] and Mitozytrex [47] are the only FDA-approved ophthalmic formulations of MMC [24]. These are not allowed in Europe, where traditionally MMC is used off-label for ophthalmic purposes, and is freshly prepared by the hospital pharmacist prior to the scheduled surgery.

\section{MMC administration during GFS and its results}

During GFS, MMC solution is administered to the eye, at the location of the planned filtering bleb. It is known to be highly bioavailable for the target tissue $\left[18,28^{-}\right]$. The MMC is mostly applicated by inserting a sponge soaked in a concentration of 0.1 to $0.5 \mathrm{mg} /$ ml MMC underneath a conjunctival/Tenon's flap onto the sclera, for 1 to 5 min [48]. For example, a sponge soaked in $0.2 \mathrm{mg} / \mathrm{ml} \mathrm{MMC} \mathrm{for} 2$ to $3 \mathrm{~min}$ is the standard intraoperative treatment in for example many European sites (also at the University Eye Clinic Maastricht). Clinical studies have observed that most tissues become saturated with MMC after an intraoperative treatment of 1 min [24]. Furthermore, IOP levels in patients after GFS were similar between the conditions where MMC was used for 2 or $5 \mathrm{~min}$ [24]. In addition, sometimes MMC is also administered postoperatively by $0.1 \mathrm{ml}$ subconjunctival injections of a $0.02 \mathrm{mg} / \mathrm{ml}$ solution (needling procedure) [48].

$\mathrm{Xi}$ et al. [49] reported that MMC is the most effective and popular anti proliferative drug for GFS, especially in eyes with high risk of failure. Intraoperative MMC treatment is effective in $90 \%$ of the GFSs whereby the created outflow pathway is open (meaning: MMC was able to inhibit the formation of fibrotic tissue after trabeculectomy and MIGS, which otherwise would close/block the outflow of $\mathrm{AqH}$ from the anterior chamber through the ostium (or MIGS shunt) into the filtering bleb) and the IOP remains in the normal-ranges $(<15 \mathrm{mmHg}$ for trabeculectomy).

\section{Mechanistic aspects of MMC-treatment in GFS}

MMC can function in GFS due to the alkylating effect of the drug [24,26,32]. Thereby, it inhibits cell proliferation/differentiation (e.g. fibroblasts into myofibroblasts; phase 3 of the wound healing process), kills cells (phase 1-3 of the wound healing process), and inhibits induction of inflammation (phase 2 of the wound healing process) $[8,18,24$, $31,33,36,39]$. A direct effect of MMC on the differentiation into M1-macrophages (pro-inflammatory; TNF- $\alpha$ ) and M2-macrophages (anti-inflammatory; IL-10 and CD163) type macrophages has not been 
studied yet. Most interestingly, MMC represents the most efficacious antifibrotic agent that is used as intraoperative treatment to attenuate the formation of fibrosis after trabeculectomy and to prolong the bleb survival [50]. Furthermore, fibroblasts of the Tenon's capsule are critical to the production of new extracellular matrix (such as collagen and glycosaminoglycans) in response to surgery $[51,52]$. Intraoperative MMC treatment inhibits the proliferation of these fibroblasts of Tenon's capsule $[51,53,54]$.

In general, MMC inhibits processes in wound healing such as collagen synthesis, fibroblast migration and fibroblast proliferation (myofibroblast formation) $[51,52,55]$. Therefore, the artificial drainage passage will not be blocked by fibrotic tissue and $\mathrm{AqH}$ can freely flow out of the anterior chamber, which leads to an IOP reduction.

\section{Failure of MMC-treatment}

Overall, $10 \%$ of the GFSs fail within the first year and this is mostly caused by the formation of fibrotic tissue in/under the filtering bleb [56]. Clearly then, the current medication regimen is not fully effective in preventing fibrosis after GFS. Possible explanations of the failures could be: (1) MMC treatment is too short to prevent the formation of fibrotic tissue, (2) presence of pro-fibrotic agents in the $\mathrm{AqH}$, (3) variation between patients, (4) toxic side effects of MMC treatment. Finally, fifth, it may be that MMC is not the optimal GFS medication after all.

\section{MMC treatment is too short}

The first reason for a GFS failure could be that the intraoperative MMC treatment is not sustained long enough to prevent fibrosis, considering for example that phase 3 of the wound healing process normally occurs after 5 to 7 days. There are several indications that the current onetime administration (within safe limits of concentration and duration) may not provide sustained levels of MMC. First, MMC has a relatively short half-life of plasma distribution (2-10 min) [26]. Second, MMC has a relatively short biological half-life (8-48 min) [36]. Third, MMC has a relatively rapid elimination time (25-90 min) $[26,47]$. Finally, the intraoperative MMC treatment and the corresponding rinsing techniques during GFS can result in quite variable local tissue levels of MMC; it may also vary considerably among surgeons [8]. In conclusion, MMC is rapidly cleared, has a fast half-life time, and the level of MMC present in the eye can differ between each GFS. All of these factors can contribute to why some patients fail after GFS and others do not. Off course, also variation between patients, will contribute to this.

\section{Presence of pro-fibrotic agents in the $\mathrm{AqH}$}

Second, the tissue of the filtering bleb is continuously exposed to $\mathrm{AqH}$ drained from the anterior chamber. This contact normally does not occur, because AqH drains directly into Schlemm's canal and is carried away by the circulation. Multiple studies have shown that $\mathrm{AqH}$ of glaucoma patients contains a number of inflammatory cytokines, including IL-6 [57], IL-8 [57-59], TNF- $\alpha$ [60], serum amyloid A (SAA) [59], and the growth factor TGF- $\beta 1$ $[59,61-65]$. Expression changes of the ocular inflammatory cytokines (including TNF- $\alpha$, IL-8, and SAA) and the growth factor TGF- $\beta 1$ in $\mathrm{AqH}$, are known to play a role in IOP elevations in patients with primary open angle glaucoma [63]. These inflammatory cytokines and growth factors influence the wound healing response (namely, stimulating inflammation (phase 2) and proliferation (phase 3)), as described in paragraph about 'GFS and cause of failures'. TGF- $\beta$ is known to induce the transdifferentiation of fibroblasts into myofibroblasts $[4,9,15,16]$. In conclusion, the continuous exposure of the filtering bleb to 'glaucomatous' $\mathrm{AqH}$ that contains increased inflammatory cytokines and TGF- $\beta 1$ will lead to a continuation of inflammation, proliferation, and finally fibrosis of the wound healing process and could therefore be one of the reasons why some patients will develop fibrotic tissue in such a manner that it will block the AqH outflow. This mechanism also could account for the fact that failure still occurs in cases long after GFS.

\section{Variation between patients}

Third, it is questionable whether the intraoperative MMC-treatment is equally effective in each individual, since MMC effectivity is p53- [32], $\mathrm{pH}$ - [18,24], and $\left[\mathrm{O}_{2}\right]-[26]$ dependent. Cheng et al. clearly showed that MMC deactivates Akt, which is known as a key player in cellular processes (such as glucose metabolism, apoptosis, cell proliferation, transcription, and cell migration), in a p53-dependent way, because Akt levels were only inhibited by MMC in MCF-7 (p53-proficient) cells and not in K562 (p53deficient) cells [32]. Furthermore, Mudhol et al. [18] and Velpandian et al. [66] reported that MMC is inactivated in acidic solutions $(\mathrm{pH}$ of 6$)$ and is mostly active at neutral $\mathrm{pH}$ (pH of 7). Most interestingly, in 1984, Coles and Jaros [67] reported that ocular surface $\mathrm{pH}$ shifted during the day and also differs between individuals. In addition, Verweij and Pinedo [26] reported that MMC is mainly active under anaerobic circumstances (low $\mathrm{O}_{2}$ values, hypoxia). Most likely, this MMC activity under hypoxic conditions is an important reason why MMC is 
effective in killing cancer cells, because it is generally known that cancer cells survive under hypoxic conditions $[68,69]$. In addition, as described in paragraph about 'MMC treatment is too short', the intraoperative MMC treatment and the washing techniques can differ between surgeries, which lead to different levels of MMC in the eye between individual surgeries [8]. Finally, patients differ also in fibrosis propensity due to for example differences in age, ethnicity, premedication, and genetic differences [16]. In conclusion, the inter-individual variability between patients regarding dose and activation of MMC as well as variations in the fibrosis process itself may result in variation in extent and timing of fibrosis and thus of failures between patients.

\section{Toxic side effects}

Fourthly, MMC treatment has several side effects. It is known that MMC is toxic to cells (e.g. hepatotoxicity) [36]. Systemic MMC treatment has several known side effects such as delayed myelosuppression, thrombocytopenia, leukocytopenia, and anemia [26,37]. Ocular use of MMC can lead to a variety of ocular complications mostly related to the typical thin-walled MMC filtering blebs, including blebitis, endophthalmitis, corneal epithelial defects, and hypotony with accompanying vision loss $[10,18,33,49]$. In conclusion, some failures may result from toxic side effects of MMC. Furthermore, the mechanism of action of MMC is relatively harsh and unspecific, which means that it will also kill and inhibit cell growth of cells that would have a beneficial effect (such as the sub-conjunctival blood- and lymph-vessels that can transport/absorb the AqH of the filtering bleb).

\section{Improvements of GFS medication regime}

Clearly then, the current GFS medication regime is not fully effective in all patients. Roughly two different approaches have been taken to improve the success rate.

The first approach is to repeat or extend the duration of the administration of the currently used antifibrotic drugs. In fact, in case of failure or threat of failure, needle revisions (i.e. subconjunctival fibrotic strands are cut with a needle and an antifibrotic drug is applied again by subconjunctival injection) are often performed in the clinic. If necessary, this treatment can be repeated at various time points, sometimes long after surgery. For these needle revisions mostly 5 -FU has been used, but also MMC needle revisions are performed, for example after a trabeculectomy and XEN gel stent surgeries [70-74,75",76-82]. Some examples of 5-FU and MMC needle revisions are shown in Table 1 . It shows that needle revisions, with MMC or 5-FU of failing

Table 1. List of needle revisions with 5-fluorouracil (5-FU) or mitomycin C (MMC) (1-6; examples of needle revisions after trabeculectomy and 7-13; examples of needle revisions after XEN gel stent surgeries)

\begin{tabular}{|c|c|c|c|c|c|c|c|c|}
\hline & \multirow[b]{2}{*}{ Surgery procedure } & \multirow[b]{2}{*}{ Origin } & \multirow[b]{2}{*}{ Intraoperative treatment } & \multicolumn{3}{|c|}{ Needle revision } & \multirow[b]{2}{*}{ Effect/success rates } & \multirow[b]{2}{*}{ Reference } \\
\hline & & & & Drugs & Concentration & Volume & & \\
\hline \multirow[t]{2}{*}{1} & Trabeculectomy & Human & $\begin{array}{l}M M C(0.4 \mathrm{mg} / \mathrm{ml} \\
1-2 \mathrm{~min})\end{array}$ & $5-\mathrm{FU}$ & $50 \mathrm{mg} / \mathrm{ml}$ & $0.1 \mathrm{ml}$ & $34,3 \%$ (after 12 months) & [76] \\
\hline & & & & $M M C$ & $0.2 \mathrm{mg} / \mathrm{ml}$ & $0.1 \mathrm{ml}$ & $57,5 \%$ (after 12 months) & \\
\hline 2 & Trabeculectomy & Human & - & $M M C$ & $80 \mu \mathrm{g} / \mathrm{ml}$ & $0.1 \mathrm{ml}$ & $76 \%$ & [77] \\
\hline 3 & Trabeculectomy & Human & - & MMC & $0.02 \%$ & $0.15-0.2 \mathrm{ml}$ & $40,3 \%$ (after 3 years) & [75"'] \\
\hline \multirow[t]{2}{*}{4} & Trabeculectomy & Human & - & $5-\mathrm{FU}$ & $50 \mathrm{mg} / \mathrm{ml}$ & $0.1 \mathrm{ml}$ & $47 \%$ & [70] \\
\hline & & & & $M M C$ & $0.2 \mathrm{mg} / \mathrm{ml}$ & $0.1 \mathrm{ml}$ & $80 \%$ & \\
\hline 5 & Trabeculectomy & Human & - & $M M C$ & $0.3 \mathrm{mg} / \mathrm{ml}(60 \mu \mathrm{g})$ & $0.2 \mathrm{ml}$ & $84.6 \%$ (after 2 years) & [78] \\
\hline \multirow[t]{2}{*}{6} & Trabeculectomy & Primates & $\begin{array}{l}\mathrm{MMC}(0.27 \mathrm{mg} / \\
\mathrm{ml}, 4 \mathrm{~min})\end{array}$ & - & - & - & - & [71] \\
\hline & & & & $M M C$ & $0.4 \mathrm{mg} / \mathrm{ml}$ & - & - & \\
\hline \multirow[t]{2}{*}{7} & XEN140 & Human & - & \multirow{2}{*}{\multicolumn{3}{|c|}{$5-\mathrm{FU}$ and $M M C$ in $32 \%$ of cases }} & - & [82] \\
\hline & XEN63 & & & & & & & \\
\hline 8 & XEN140 & Human & - & \multicolumn{3}{|c|}{5 -FU and $M M C$ in $43 \%$ of cases } & - & [81] \\
\hline 9 & XEN45 & Human & MMC & \multicolumn{3}{|c|}{ None } & - & [79] \\
\hline 10 & XEN45 & Human & $M M C$ & \multicolumn{3}{|c|}{5 -FU and $M M C$ in $2.4 \%$ of cases } & - & [72] \\
\hline 11 & XEN45 & Human & $M M C$ & \multicolumn{3}{|c|}{5 -FU and MMC in $43.2 \%$ of cases } & - & [80] \\
\hline 12 & XEN45 & Human & $M M C$ & \multicolumn{3}{|c|}{5 -FU and MMC in $32.3 \%$ of cases } & - & [74] \\
\hline 13 & XEN45 & Human & MMC & \multicolumn{3}{|c|}{5 -FU and $M M C$ in $30.7 \%$ of cases } & - & [73] \\
\hline
\end{tabular}

5-FU, 5-fluorouracil; MMC, mitomycin C. 


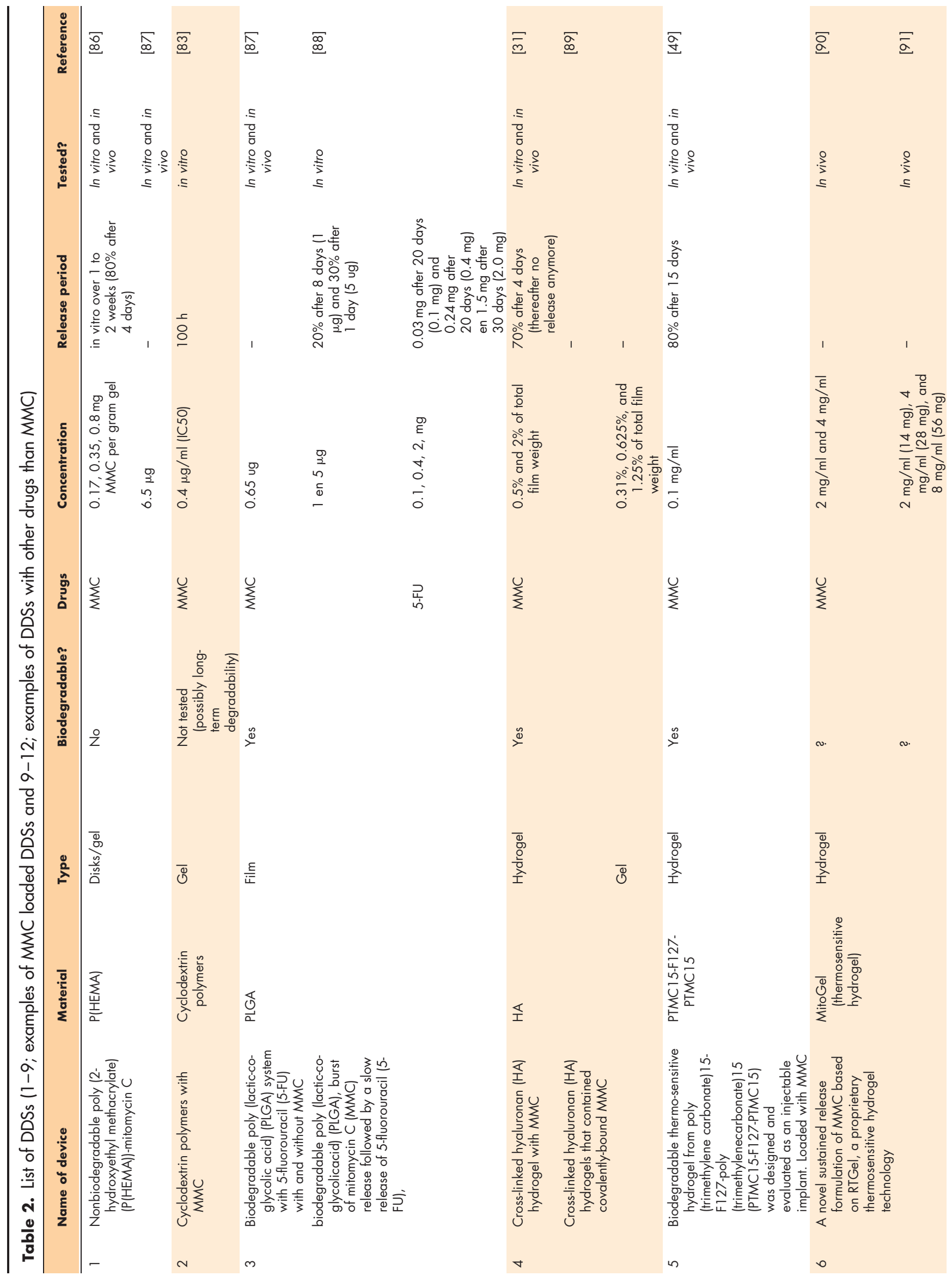




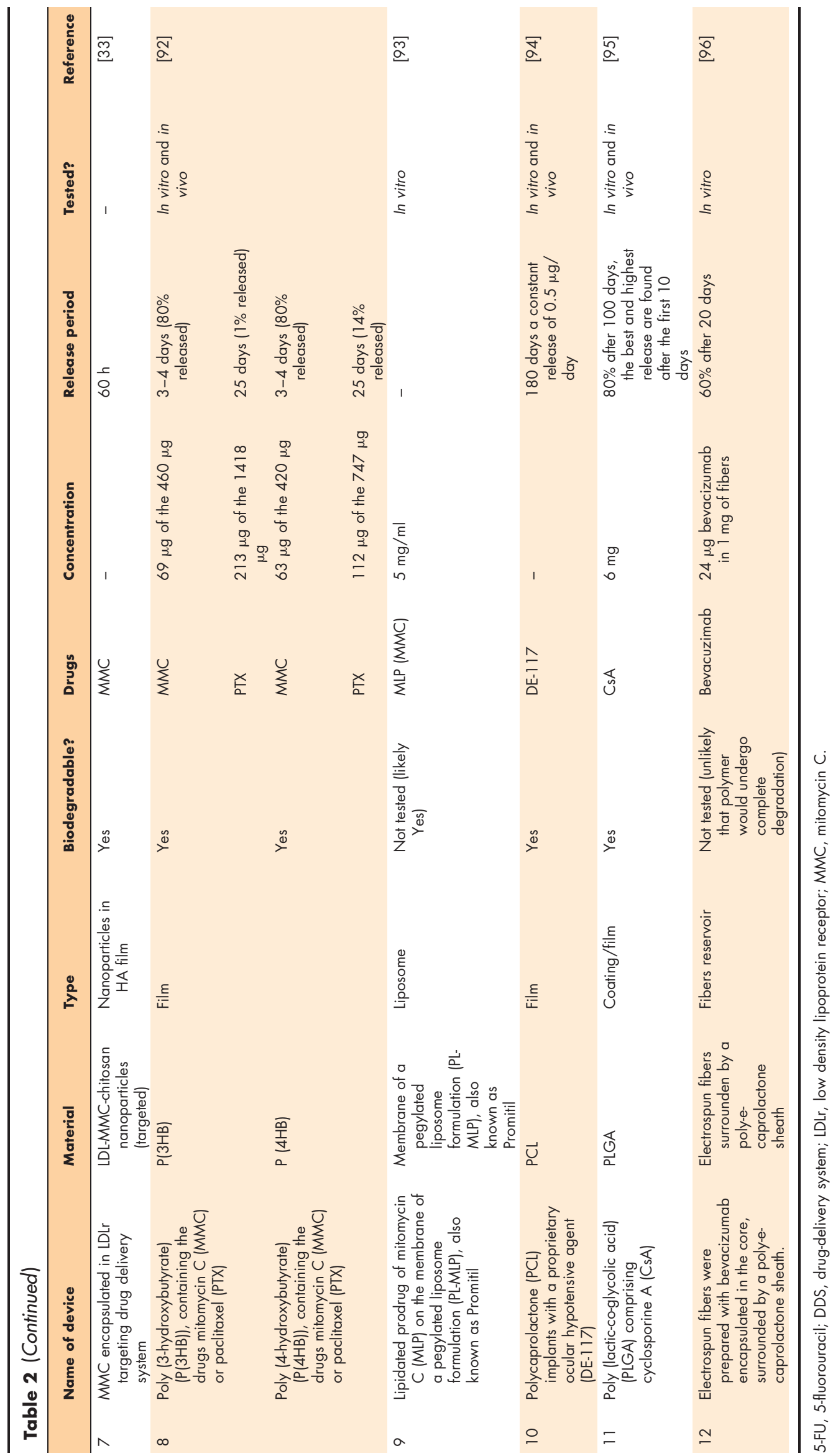


filter blebs after trabeculectomy, are successful $\left[70,71,75^{-}, 76-78\right]$. Furthermore, it shows that a needle revision with $\mathrm{MMC}$ is more effective than a needle revision with 5-FU $[70,76]$. Needle revisions, with 5-FU or MMC, are needed in $30 \%$ to $50 \%$ of all the XEN gel stent surgery cases [72-74,79-82].

The positive results of repeated administration of MMC suggest that the onetime intraoperative application of MMC is too short to curtail fibrosis in the long term. It may be better to present antifibrotic drugs by a drug delivery system (DDS) for sustained drug delivery. This sustained delivery may result in a longer and better (better controlled in dose and duration) MMC treatment than the current onetime intraoperative $\mathrm{MMC}$ treatment $[13,83,84]$. In this manner, the antifibrotic drugs are present throughout the whole wound healing process. Furthermore, a DDS with continuous delivery of MMC over a long time, may be more efficacious since fibroblasts and/or tissue are continuously exposed to AqH that contains inflammatory cytokines and an important growth factor for the inducement of the wound healing processes. Due to the long-term postoperative scar formation time, which lasts at least for over 2 weeks [85], a DDS that can maintain an effective drug concentration for an appropriate period of time to regulate postoperative proliferation and maintain bleb filtering with fewer complications is desirable [49]. Multiple sustained drug delivery systems (DDSs) have been developed in the past years. Many of these studies with the DDSs were performed within the eye of humans and/or animals. Examples of interesting DDSs are listed in Table 2: (1) a nonbiodegradable poly (2-hydroxyethyl methacrylate) (P (HEMA))MMC device [86,87], (2) cyclodextrin polymers loaded with MMC [83], (3) a biodegradable poly (lactic-co-glycolic acid) (PLGA) system with 5-FU with and without MMC $[87,88]$, (4) a cross-linked hyaluronan (HA) hydrogel that contained MMC [31,89], (5) a thermo-sensitive hydrogel from poly (trimethylene carbonate)15-F127-poly (trimethylene carbonate)15 (PTMC15-F127-PTMC15) loaded with MMC [49], (6) a thermosensitive hydrogel from MitoGel loaded with MMC [90,91], (7) MMC encapsulated in low density lipoprotein receptor targeting DDS (LDL-MMC-chitosan nanoparticles) [33], (8) thin films of two different polymers, Poly (3-hydroxybutyrate) (P (3HB)) and Poly (4-hydroxybutyrate) $(\mathrm{P}(4 \mathrm{HB}))$, containing MMC or paclitaxel (PTX) were attached to silicone-tubes [92], (9) lipidated prodrug of MMC (MLP) on the membrane of a pegylated liposome formulation (PL-MLP), also known as Promitil [93], (10) polycaprolactone implants that achieve zero-order release of a proprietary ocular hypotensive agent (DE-117) [94], (11) a PLGA system loaded with cyclosporine A [95], and (12) encapsulation of bevacuzimab in the core of electrospun fibers [96]. No DDS for sustained delivery of antifibrotic drugs is currently FDA approved. One DDS of MMC, namely PL-MLP (see also in Table 2), is now being tested in clinical trials.

The second approach to improve GFS outcome in the long term is to develop other (classes of) GFS medication $[4,15,16]$. This option will not be discussed in detail in this review. Multiple drugs have been tested in the past years, often aiming to influence the wound healing after GFS in a more specific and physiological manner (e.g. by targeting TGF- $\beta$ ) rather that the unspecific treatment with MMC. This research has extensively been reviewed by $\mathrm{Li}$ et al. [14], Schlunck et al. [9], Yu-Wai-Man and Khaw [4], and Friedlander [97]. These new GFS drugs may avoid several of the side effects of MMC and maybe also the individual variability between patients. In the future, medication may be personalized taking account of individual differences in fibrosis [98].

\section{CONCLUSION}

GFS is currently the last resort treatment to stop or limit vision loss in patients that suffer from glaucoma. A major complication, which frequently causes failure of GFS, is the formation of fibrosis in the filtering bleb. The antifibrotic drug MMC, given as an adjuvant during GFS, has significantly increased GFS success rates. MMC is also used in GFS surgery with the novel minimally invasive glaucoma surgical (MIGS) devices.

Although MMC certainly improved GFS success rates, still roughly $10 \%$ of bleb-based MIGS surgeries with a onetime MMC application fail within the first year, mostly because of fibrosis in the filtering bleb. To further reduce GFS failure rate, we roughly have two options: either we improve the MMC application or we switch to new drugs. Treatment of GFS failures with repeated injections of MMC shows positive results. This suggests that prolonged presence of MMC may control fibrosis over a longer period of time. DDSs for sustained release of MMC are currently being developed and these will show if this hypothesis is true. If not, we need to implement new approaches and drugs to create a suitable GFS wound healing, which will further increase GFS success rate.

\section{Acknowledgements}

None.

\section{Financial support and sponsorship}

This work was supported by the framework of the Chemelot Institute for Science and Technology (InSciTe) under Grant BM3.03 SEAMS. 


\section{Conflicts of interest}

H.J.M.B.: Glaukos (Consultancy, Research support), InnFocus, Inc., a Santen Company (Consultancy, Research Support), Santen (Consultancy), and Alcon (Research support). C.A.B.W.: Alcon/Novartis (Grant support, Consultancy), Santen (Grant support), and Thea Pharma (Grant support, Consultancy). L.P.: InnFocus, Inc., a Santen Company (Personal financial interest). T.G.M.F.G., J.E.J.W., R.J.S.v.M., and R.A.M.: none.

\section{REFERENCES AND RECOMMENDED \\ $R=A D \| N G$}

Papers of particular interest, published within the annual period of review, have been highlighted as:

- of special interest

- of outstanding interest

1. Mansouri K, Medeiros FA, Weinreb RN. Global rates of glaucoma surgery. Graefe's archive for clinical and experimental ophthalmology = Albrecht von Graefes Archiv fur klinische und experimentelle. Ophthalmologie 2013; 251:2609-2615.

2. Braunger BM, Fuchshofer R, Tamm ER. The aqueous humor outflow pathways in glaucoma: A unifying concept of disease mechanisms and causative treatment. Eur J Pharm Biopharm 2015; 95(Pt B):173-181.

3. Weinreb RN, Aung T, Medeiros FA. The pathophysiology and treatment of glaucoma: a review. Jama 2014; 311:1901-1911.

4. Yu-Wai-Man C, Khaw PT. Developing novel antifibrotic therapeutics to modulate postsurgical wound healing in glaucoma: big potential for small molecules. Expert Rev Ophthalmol 2015; 10:65-76.

5. Lang GK. Ophthalmology: a pocket textbook atlas, 2nd edition. Clin Exp Optom 2008; 91:126.

6. Jonas JB, Aung T, Bourne RR, et al. Glaucoma. Lancet 2017; 390:2183-2193.

7. King A, Azuara-Blanco A, Tuulonen A. Glaucoma. BMJ 2013; 346:f3518.

8. Hung $P$. Mitomycin- $C$ in glaucoma filtering surgery. Asia Pac J Ophthalmol 2000; 2 .

9. Schlunck G, Meyer-ter-Vehn T, Klink T, Grehn F. Conjunctival fibrosis following filtering glaucoma surgery. Exp Eye Res 2016; 142:76-82.

10. Martorana GM, Schaefer JL, Levine MA, et al. Sequential therapy with saratin, bevacizumab and ilomastat to prolong bleb function following glaucoma filtration surgery in a rabbit model. PLoS One 2015; 10:e0138054.

11. Mantravadi AV, Vadhar N. Glaucoma. Prim Care 2015; 42:437-449.

12. Chang MR, Cheng $Q$, Lee DA. Basic science and clinical aspects of wound healing in glaucoma filtering surgery. J Ocular Pharmacol Ther 1998; 14:75-95.

13. Patel S, Pasquale LR. Glaucoma drainage devices: a review of the past, present, and future. Semin Ophthalmol 2010; 25:265-270.

14. Li X, Zhu L, Wang $B$, et al. Drugs and targets in fibrosis. Front Pharmacol $2017 ; 8: 855$

15. Lockwood A, Brocchini S, Khaw PT. New developments in the pharmacological modulation of wound healing after glaucoma filtration surgery. Curr Opin Pharmacol 2013; 13:65-71.

16. Seibold LK, Sherwood MB, Kahook MY. Wound modulation after filtration surgery. Survey of ophthalmology 2012; 57:530-550.

17. Mearza AA, Aslanides IM. Uses and complications of mitomycin $C$ in ophthalmology. Expert Opin Drug Safety 2007; 6:27-32.

18. Mudhol R, Zingade N, Mudhol R. Mitomycin C in ophthalmology. J Sci Soc 2012; 39:4-6

19. Bar-David L, Blumenthal EZ. Evolution of glaucoma surgery in the last 25

I. years. Rambam Maimonides Med J 2018; 9:e0024.

This paper gives a perfect overview about the evolution of glaucoma surgeries in last 25 years.

20. Lavia $C$, Dallorto $L$, Maule $M$, et al. Minimally-invasive glaucoma surgeries (MIGS) for open angle glaucoma: A systematic review and meta-analysis. PLoS One 2017; 12:e0183142.

21. Ansari $E$. An update on implants for minimally invasive glaucoma surgery (MIGS). Ophthalmol Ther 2017; 6:233-241.

22. Saheb $\mathrm{H}$, Ahmed II. Micro-invasive glaucoma surgery: current perspectives and future directions. Curr Opin Ophthalmol 2012; 23:96-104.

23. Batlle JF, Fantes $F$, Riss $I$, et al. Three-year follow-up of a novel aqueous humor MicroShunt. J Glaucoma 2016; 25:e58-e65.

24. Al Habash A, Aljasim LA, Owaidhah O, Edward DP. A review of the efficacy of mitomycin C in glaucoma filtration surgery. Clin Ophthalmol 2015; 9:1945-1951.

25. Tomasz M. Mitomycin C: small, fast and deadly (but very selective). Chem Biol $1995 ; 2: 575-579$
26. Verweij J, Pinedo HM. Mitomycin C: mechanism of action, usefulness and limitations. Anticancer Drugs 1990; 1:5-13.

27. Bargonetti J, Champeil E, Tomasz M. Differential toxicity of DNA adducts of mitomycin C. Journal of nucleic acids 2010; 2010:698960.

28. Fang YP, Hu PY, Huang YB. Diminishing the side effect of mitomycin $C$ by using $\mathrm{pH}$-sensitive liposomes: in vitro characterization and in vivo pharmacokinetics. Drug Design Dev Ther 2018; 12:159-169.

This paper states some important properties of mitomycin $C$ and it gives a nice example on how you can release mitomycin $\mathrm{C}$ in your region of interest.

29. Crooke ST, Bradner WT. Mitomycin C: a review. Cancer Treatment Rev 1976; 3:121-139.

30. Myers AL, Zhang Y-P, Kawedia JD, et al. Solubilization and stability of mitomycin $\mathrm{C}$ solutions prepared for intravesical administration. Drugs R\&D 2017; 17:297-304

31. Li H, Liu Y, Shu XZ, et al. Synthesis and biological evaluation of a cross-linked hyaluronan-mitomycin C hydrogel. Biomacromolecules 2004; 5:895-902.

32. Cheng SY, Vargas A, Lee JY, et al. Involvement of Akt in mitomycin $C$ and its analog triggered cytotoxicity in MCF-7 and K562 cancer cells. Chem Biol Drug Des 2018; 92:2022-2034

33. Shao T, Li X, Ge J. Target drug delivery system as a new scarring modulation after glaucoma filtration surgery. Diagn Pathol 2011; 6:64.

34. Mitomycin [updated Drug created on June 13, 2005 07:24/Updated on October 28, 2018 07:22]. Available from: https://www.drugbank.ca/drugs/ DB00305.

35. Hoorn CM, Wagner JG, Petry TW, Roth RA. Toxicity of mitomycin C toward cultured pulmonary artery endothelium. Toxicol Appl Pharmacol 1995; 130:87-94

36. National Center for Biotechnology Information. PubChem Compound Database; $\mathrm{CID}=5746$, https://pubchem.ncbi.nlm.nih.gov/compound/5746 (Accessed October 30, 2018)

37. Bradner WT. Mitomycin C: a clinical update. Cancer Treat Rev 2001; $27: 35-50$.

38. den Hartigh J, McVie JG, van Oort WJ, Pinedo HM. Pharmacokinetics of mitomycin C in humans. Cancer Res 1983; 43:5017-5021.

39. Kersey JP, Vivian AJ. Mitomycin and amniotic membrane: a new method of reducing adhesions and fibrosis in strabismus surgery. Strabismus 2008; $16: 116-118$.

40. Sadruddin O, Pinchuk L, Angeles R, Palmberg P. Ab externo implantation of the MicroShunt, a poly (styrene-block-isobutylene-block-styrene) surgical device for the treatment of primary open-angle glaucoma: a review. Eye Vis 2019; 6:36.

41. Chen $\mathrm{CW}$. Enhanced intraocular pressure controlling effectiveness of trabeculectomy by local application of mitomycine-C. Trans Asia Pac Acad Ophthalmol 1983; (9):172-173.

42. Chen CW, Huang HT, Bair JS, Lee CC. Trabeculectomy with simultaneous topical application of mitomycin-C in refractory glaucoma. J Ocul Pharmacol 1990; 6:175-182.

43. Hung PT, Lin LL, Hsieh JW, Wang TH. Preoperative mitomycin-C subconjunctival injection and glaucoma filtering surgery. J Ocul Pharmacol Ther 1995; 11:233-241.

44. Siriwardena D, Edmunds B, Wormald RP, Khaw PT. National survey of antimetabolite use in glaucoma surgery in the United Kingdom. $\mathrm{Br} \mathrm{J}$ Ophthalmol 2004; 88:873-876.

45. Desai MA, Gedde SJ, Feuer WJ, et al. Practice preferences for glaucoma surgery: a survey of the American Glaucoma Society in 2008. Ophthalmic Surg Lasers Imaging 2011; 42:202-208.

46. Mitomycin solution (Mitosol) for glaucoma surgery. The Medical letter on drugs and therapeutics 2013; 55:24.

47. FDA approves extra safe chemotherapy drug. Expert review of anticancer therapy $2002 ; 2: 618-619$

48. European Glaucoma Society. Terminology and Guidelines for Glaucoma, 4th Edition - Chapter 3: Treatment principles and options. Supported by the EGS Foundation. Br J Ophthalmol 2017; 101:130-195.

49. Xi L, Wang $\mathrm{T}$, Zhao $\mathrm{F}$, et al. Evaluation of an injectable thermosensitive hydrogel as drug delivery implant for ocular glaucoma surgery. PLoS One 2014; 9:e100632.

50. Razeghinejad MR, Fudemberg SJ, Spaeth GL. The changing conceptual basis of trabeculectomy: a review of past and current surgical techniques. Survey of ophthalmology 2012; 57:1-25.

51. Beatty S, Potamitis T, Kheterpal S, O'Neill EC. Trabeculectomy augmented with mitomycin C application under the scleral flap. Br J Ophthalmol 1998; 82:397-403.

52. Costa VP, Spaeth GL, Eiferman RA, Orengo-Nania S. Wound healing modulation in glaucoma filtration surgery. Ophthal Surg 1993; 24:152-170.

53. Jampel HD. Effect of brief exposure to mitomycin $\mathrm{C}$ on viability and proliferation of cultured human Tenon's capsule fibroblasts. Ophthalmology 1992; 99:1471-1476.

54. Yamamoto T, Varani J, Soong HK, Lichter PR. Effects of 5-fluorouracil and mitomycin $\mathrm{C}$ on cultured rabbit subconjunctival fibroblasts. Ophthalmology 1990; 97:1204-1210.

55. Smith S, D'Amore PA, Dreyer EB. Comparative toxicity of mitomycin C and 5fluorouracil in vitro. Am J Ophthalmol 1994; 118:332-337.

56. Mokhles $\mathrm{P}$, Schouten JS, Beckers HJ, et al. A systematic review of end-of-life visual impairment in open-angle glaucoma: an epidemiological autopsy. J Glaucoma 2016; 25:623-628. 
57. Zenkel M, Lewczuk $P$, Junemann $A$, et al. Proinflammatory cytokines are involved in the initiation of the abnormal matrix process in pseudoexfoliation syndrome/glaucoma. Am J Pathol 2010; 176:2868-2879.

58. Kuchtey J, Rezaei KA, Jaru-Ampornpan $P$, et al. Multiplex cytokine analysis reveals elevated concentration of interleukin- 8 in glaucomatous aqueous humor. Invest Ophthalmol Vis Sci 2010; 51:6441-6447.

59. Takai $Y$, Tanito M, Ohira A. Multiplex cytokine analysis of aqueous humor in eyes with primary open-angle glaucoma, exfoliation glaucoma, and cataract. Invest Ophthalmol Vis Sci 2012; 53:241-247.

60. Sawada H, Fukuchi T, Tanaka T, Abe H. Tumor necrosis factor-alpha concentrations in the aqueous humor of patients with glaucoma. Invest Ophthalmol Vis Sci 2010; 51:903-906.

61. Picht G, Welge-Luessen U, Grehn F, Lutjen-Drecoll E. Transforming growth factor beta 2 levels in the aqueous humor in different types of glaucoma and the relation to filtering bleb development. Graefe's Arch Clin Exp Ophthalmol 2001; 239:199-207.

62. Huang $W$, Chen $S$, Gao X, et al. Inflammation-related cytokines of aqueous humor in acute primary angle-closure eyes. Invest Ophthalmol Vis Sci 2014; 55:1088-1094.

63. Khalef $\mathrm{N}$, Labib $\mathrm{H}$, Helmy $\mathrm{H}$, et al. Levels of cytokines in the aqueous humor of eyes with primary open angle glaucoma, pseudoexfoliation glaucoma and cataract. Electron Physician 2017; 9:3833-3837.

64. Zheng Y, Rao Y-Q, Li J-K, et al. Age-related pro-inflammatory and proangiogenic changes in human aqueous humor. Int J Ophthalmol 2018; $11: 196-200$.

65. Chua J, Vania M, Cheung CM, et al. Expression profile of inflammatory cytokines in aqueous from glaucomatous eyes. Molecular vision 2012; 18:431-438.

66. Velpandian T, Saluja V, Ravi AK, et al. Evaluation of the stability of extemporaneously prepared ophthalmic formulation of mitomycin C. J Ocul Pharmacol Ther 2005; 21:217-222.

67. Coles WH, Jaros PA. Dynamics of ocular surface pH. Br J Ophthalmol 1984; 68:549-552.

68. Yttersian Sletta K, Tveitarås MK, Lu N, et al. Oxygen-dependent regulation of tumor growth and metastasis in human breast cancer xenografts. PLoS One 2017; 12:e0183254.

69. Brown JM. The Hypoxic Cell. Cancer Res 1999; 59:5863.

70. Anand N, Khan A. Long-term outcomes of needle revision of trabeculectomy blebs with mitomycin $\mathrm{C}$ and 5-fluorouracil: a comparative safety and efficacy report. J Glaucoma 2009; 18:513-520.

71. Bair JS, Chen CW. Trabeculectomy with multiple applications of mitomycin-C in monkeys with experimental glaucoma. J Ocul Pharmacol Ther 1997; $13: 115-128$.

72. De Gregorio A, Pedrotti E, Russo L, Morselli S. Minimally invasive combined glaucoma and cataract surgery: clinical results of the smallest ab interno gel stent. Int Ophthalmol 2018; 38:1129-1134.

73. Galal A, Bilgic A, Eltanamly R, Osman A. XEN Glaucoma Implant with Mitomycin C 1-Year Follow-Up: Result and Complications. J Ophthalmol 2017; 2017:5457246.

74. Grover DS, Flynn WJ, Bashford KP, et al. Performance and safety of a new ab interno gelatin stent in refractory glaucoma at 12 months. Am J Ophthalmol 2017; 183:25-36

75. Lin S, Byles D, Smith M. Long-term outcome of mitomycin C-augmented

- needle revision of trabeculectomy blebs for late trabeculectomy failure. Eye 2018; 32:1893-1899.

This paper clearly indicates that mitomycin $C$ injections has a positive effect on bleb survival.

76. Liu W, Wang J, Zhang M, et al. Comparison of Subconjunctival Mitomycin C and 5-Fluorouracil Injection for Needle Revision of Early Failed Trabeculectomy Blebs. Journal of ophthalmology 2016; 2016:3762674.

77. Maestrini HA, Cronemberger S, Matoso HD, et al. Late needling of flat filtering blebs with adjunctive mitomycin C: efficacy and safety for the corneal endothelium. Ophthalmology 2011; 118:755-762.
78. Pathak-Ray V, Choudhari N. Rescue of failing or failed trabeculectomy blebs with slit-lamp needling and adjunctive mitomycin $\mathrm{C}$ in Indian eyes. Indian journal of ophthalmology 2018; 66:71-76.

79. Perez-Torregrosa VT, Olate-Perez A, Cerda-lbanez M, et al. Combined phacoemulsification and XEN45 surgery from a temporal approach and 2 incisions. Archivos de la Sociedad Espanola de Oftalmologia 2016; 91:415-421.

80. Schlenker MB, Gulamhusein $\mathrm{H}$, Conrad-Hengerer l, et al. Efficacy, Safety, and Risk Factors for Failure of Standalone Ab Interno Gelatin Microstent Implantation versus Standalone Trabeculectomy. Ophthalmology 2017; 124:1579-1588.

81. Sheybani A, Dick HB, Ahmed II. Early Clinical Results of a Novel Ab Interno Gel Stent for the Surgical Treatment of Open-angle Glaucoma. Journal of glaucoma 2016; 25:e691-e696.

82. Sheybani $A$, Lenzhofer $M$, Hohensinn M, et al. Phacoemulsification combined with a new ab interno gel stent to treat open-angle glaucoma: Pilot study. Journal of Cataract \& Refractive Surgery 2015; 41:1905-1909.

83. Merritt SR, Velasquez G, von Recum HA. Adjustable release of mitomycin C for inhibition of scar tissue formation after filtration surgery. Experimental eye research 2013; 116:9-16.

84. Schmidt W, Kastner C, Sternberg K, et al. New concepts for glaucoma implants-controlled aqueous humor drainage, encapsulation prevention and local drug delivery. Curr Pharm Biotechnol 2013; 14:98-111.

85. Hollo G. Wound healing and glaucoma surgery: modulating the scarring process with conventional antimetabolites and new molecules. Dev Ophthalmol 2012; 50:79-89.

86. Sahiner N, Kravitz DJ, Qadir R, et al. Creation of a drug-coated glaucoma drainage device using polymer technology: in vitro and in vivo studies. Arch Ophthalmol 2009; 127:448-453.

87. Schoenberg ED, Blake DA, Swann FB, et al. Effect of two novel sustainedrelease drug delivery systems on bleb fibrosis: an in vivo glaucoma drainage device study in a rabbit model. Transl Vis Sci Technol 2015; 4:4.

88. Ponnusamy $\mathrm{T}, \mathrm{Yu} \mathrm{H}$, John VT, et al. A novel antiproliferative drug coating for glaucoma drainage devices. J Glaucoma 2014; 23:526-534.

89. Liu $Y, L i ~ H, ~ S h u ~ X Z$, et al. Crosslinked hyaluronan hydrogels containing mitomycin $\mathrm{C}$ reduce postoperative abdominal adhesions. Fertil Steril 2005; 83(suppl 1):1275-1283.

90. Donin NM, Duarte S, Lenis AT, et al. Sustained-release formulation of mitomycin $\mathrm{c}$ to the upper urinary tract using a thermosensitive polymer: a preclinical study. Urology 2017; 99:270-277.

91. Donin NM, Strauss-Ayali D, Agmon-Gerstein $Y$, et al. Serial retrograde instillations of sustained release formulation of mitomycin $C$ to the upper urinary tract of the Yorkshire swine using a thermosensitive polymer: Safety and feasibility. Urol Oncol 2017; 35:272-278.

92. Hovakimyan M, Siewert S, Schmidt W, et al. Development of an experimental drug eluting suprachoroidal microstent as glaucoma drainage device. Transl Vis Sci Technol 2015; 4:14.

93. Wei $X$, Patil $Y$, Ohana $P$, et al. Characterization of pegylated liposomal mitomycin $\mathrm{C}$ lipid-based prodrug (Promitil) by high sensitivity differential scanning calorimetry and cryogenic transmission electron microscopy. Mol Pharm 2017; 14:4339-4345.

94. Kim J, Kudisch M, Mudumba S, et al. Biocompatibility and pharmacokinetic analysis of an intracameral polycaprolactone drug delivery implant for glaucoma. Invest Ophthalmol Vis Sci 2016; 57:4341-4346.

95. Dai Z, Yu X, Hong J, et al. Development of a novel CsA-PLGA drug delivery system based on a glaucoma drainage device for the prevention of postoperative fibrosis. Mater Sci Eng C Mater Biol Appl 2016; 66:206-214.

96. Angkawinitwong U, Awwad S, Khaw PT, et al. Electrospun formulations of bevacizumab for sustained release in the eye. Acta Biomater 2017; 64:126-136.

97. Friedlander M. Fibrosis and diseases of the eye. J Clin Invest 2007; 117:576-586.

98. Yu-Wai-Man C, Khaw PT. Personalized medicine in ocular fibrosis: myth or future biomarkers. Adv Wound Care 2016; 5:390-402. 